\title{
Age-associated functional morphology of thyroid and its impact on the expression of vimentin, cytokeratins and VEGF. The role of nigella in refinement
}

\author{
Sherif Mohamed Zaki ${ }^{1,2}$, Enas Ahmed Mohamed ${ }^{1}$, Shereen Abdel Fattah', \\ Hend Abdullah $^{1}$, Lucyna Kaszubowska ${ }^{3}$ \\ ${ }^{1}$ Department of Anatomy and Embryology, Faculty of Medicine, Cairo University, Cairo, Egypt \\ ${ }^{2}$ Fakeeh College for Medical Sciences, Jeddah, Saudi Arabia \\ ${ }^{3}$ Department of Histology, Faculty of Medicine, Medical University of Gdansk, Gdansk, Poland
}

\begin{abstract}
Introduction. Aging causes morphological and functional changes in the thyroid gland. Free radicals play a key role in the pathology of normal aging. Vimentin and cytokeratin are cytoskeletal intermediate filaments that are often used as indirect indices of tissue injury. The aim of the study was to clarify the age-related alterations in the structure and function of the thyroid gland. The relationship between oxidative/antioxidative stress markers and cytoskeletal intermediate filaments (vimentin and cytokeratin) and oxidative/antioxidative stress markers as well as vascular endothelial growth factor (VEGF) during aging were elucidated. Finally, the role of Nigella sativa (NS) oil in ameliorating age-related alterations of the structure and function of the thyroid gland was studied. Material and methods. Thirty Sprague-Dawley albino rats were divided into five groups: young adult control, young adult NS-treated, late adult control, late adult NS-treated, and senile. The age of young adult, late adult, and senile rats was nearly 7, 18 and 22 months, respectively. NS oil was added to food pellets and was administered at a daily dose of $0.1 \mathrm{~g} / \mathrm{kg}$ body weight for one month. The thyroid gland was dissected and fixed immediately in 10\% formalin saline. The assessment of thyroid structure was based on hematoxylin and eosin, and Masson's trichrome stainings, and histomorphometric analysis of the deparaffinized sections. Localization and distribution of vimentin and cytokeratin filaments was assessed by immunohistochemistry. Measurements of VEGF gene expression by qPCR and oxidative/antioxidative markers (malondialdehyde and glutathione content, superoxide dismutase activity) in thyroid gland homogenates were performed. Serum concentration of thyroid hormones (T3, T4) and TSH were assessed by radioimmunoassay.

Results. Follicles in the late adult control group were dilated and disrupted. Follicular cells showed cytoplasmic vacuolation. Follicles in the thyroids of senile rats were of irregular shape, often with cellular exfoliations. Many follicles were dilated and lined with flattened cells. A notable amelioration of these morphological alterations was observed in late adult NS-treated rats. Decrease in serum T3 and T4 levels and increase in TSH levels were observed in the late adult control and senile groups. A clear shift of the oxidative/antioxidative markers (MDA/ /GSH, SOD) was observed in the late adult control and senile groups in favor of oxidants. Administration of NS to late adult rats resulted in normalization of these parameters. Increased area of collagen fibers, immunoreactivity of vimentin and cytokeratin filaments and VEGF gene expression were observed in the thyroids of late adult and senile rat groups as compared to young animals. The mean number of follicular cells decreased in the late adult control and senile groups. Administration of NS to the late adult rats returned these parameters to the level of the young adult rats.
\end{abstract}

\footnotetext{
Correspondence address: Sherif Mohamed Zaki

Faculty of Medicine, University of Cairo, Cairo, Egypt

Current address: Fakeeh College for Medical Sciences,

Jeddah, Saudi Arabia

e-mail: zakysherif1@gmail.com
} 
Conclusions. Aging-related alterations in both structure and function of the rat thyroid gland that are associated with increased indices of oxidative stress might be abrogated by administration of antioxidative agents present in Nigella sativa oil. (Folia Histochemica et Cytobiologica 2018, Vol. 56, No. 3, 159-171)

Key words: aging; rat; thyroid; morphology; Nigella sativa; vimentin; cytokeratin; VEGF; MDA; GSH; SOD; IHC; qPCR

\section{Introduction}

Aging is a complicated biological process that leads to gradual loss of the capability to uphold homeostasis. Accumulation of deleterious changes in the cells due to aging results in progressive tissue damage [1]. Free radicals and reactive oxygen species (ROS) have a key role in the pathology of normal aging. They are precipitated with aging and cause alterations of many tissues [2].

Some studies documented that aging causes morphological changes in the thyroid gland. In adult rats, the thyroid follicles are oval to round in shape and are lined with cuboidal to columnar cells [3]. Peripheral follicles are more hyperactive than central ones [4]. However, in elderly rats, the thyroid gland has a large number of irregularly shaped follicles. Some follicles are dilated and lined with a single layer of flat epithelial cells. In thyroids of old rats and humans, many follicles do not contain colloid or fuse to form large irregular structures $[3,5]$. Moreover, there is an obvious increment in the content of interstitial fibrous connective tissue enriched with many blood vessels in aged thyroids [6]. Increased size and number of follicles were also found in the humped camel [7]. Similarly, the thyroid in humans over the age of 60 undergoes progressive fibrosis and atrophy, leading to a reduction in the thyroid volume [8].

Vimentin and cytokeratins are cytoskeletal intermediate filaments [9]. Vimentin is a type III intermediate filament protein [10]. It is a useful marker of cell senescence [11]. Cytokeratins are more strongly immunoexpressed in thyroid carcinomas than in the normal thyroid [12]. Their expression was assumed to be an indirect marker of tissue injury [13]. Vascular endothelial growth factor (VEGF) is a cytokine secreted by various cell types that promotes angiogenesis. It aids in restoring oxygen supply to tissues triggered by insufficient circulation [14]. It has been suggested that VEGF and its receptors are present in the thyroid epithelial cells and they contribute to the regulation of the development and function of thyrocytes $[15,16]$. Increased expression of VEGF and its receptors might be crucial in the regulation of the proliferation of thyroid epithelial cells [15].
Nigella sativa (NS) is an annual flowering plant, native to Asia and the Middle East. The seed oil of NS is rich in polyphenols, tocopherols, proteins, carbohydrates, vegetable oil and omega- 3 and omega- 6 fatty acids. Potassium, calcium and sodium are the predominant mineral elements [17]. Its seeds are efficient in preventing nephrotoxicity and hepatotoxicity caused by disease and chemicals. The NS seed exhibits analgesic, antibacterial, anti-inflammatory, and antineoplastic activity [18]. In addition, NS oil was shown to have an antioxidant effect [19].

The aim of the study was to clarify age-related alterations in the structure and function of the rat thyroid gland, especially in regard to the expression of cytoskeletal intermediate filaments (vimentin and cytokeratin), VEGF mRNA level and oxidative/antioxidative stress status markers, i.e. malondialdehyde and glutathione content as well as superoxide dismutase activity (MDA/GSH, SOD). Relationships between these parameters and serum thyroid hormone and TSH concentrations were also investigated. Finally, the role of NS oil in the amelioration of age-related alterations of the thyroid gland was studied.

\section{Materials and methods}

Chemicals and dose of Nigella sativa oil. Nigella sativa (NS) oil was purchased from Cap Pharma Company, Egypt. NS oil was given at a daily dose of $0.1 \mathrm{~g} / \mathrm{kg} / \mathrm{b}$.w. orally mixed with pelleted food for one month. The dosages was chosen based on human NS oil consumption which is equal to $2 \mathrm{~g}$ /day; $0.1 \mathrm{~g} / \mathrm{kg} /$ day was accepted as the corresponding dose in rat [20].

Animals. Thirty Sprague-Dawley male albino rats weighing 250-350 g were used in this study. Animals were obtained from the animal house, Faculty of Medicine, Cairo University, Cairo, Egypt. Rats were acclimated in the laboratory for two weeks before carrying out the experiment. They were housed in special metal cages, $40 \times 30 \times 16 \mathrm{~cm}$ and exposed to a light/dark $14: 10$-hour cycle at $22-24^{\circ} \mathrm{C}$ under standard laboratory and environmental conditions. The animals were given standard rodent food pellets and water ad libitum. The study was approved by the Ethics Committee, Faculty of Medicine, and Cairo University (1561/2017). All animal procedures followed ethical guidelines for animal experi- 
ments. The study was performed according to the ethical standards of the National Institutes of Health guide for the care and use of Laboratory Animals (NIH Publications No. 8023, revised 1978).

Experimental design. Rats were divided into five groups, each consisted of 6 rats. Animals were observed twice per day for signs of mortality. The weights of each animal were recorded in the beginning and at weekly intervals until the end of the experiment.

Rats were divided according to the following scheme: young adult control group: age approximately 7 months, body mass $250 \pm 30 \mathrm{~g}$ (mean $\pm \mathrm{SD}), \mathrm{n}=6$; young adult NS-treated group: age 7 months, body mass $260 \pm 25 \mathrm{~g}$, $\mathrm{n}=6$; NS was given at a daily dose of $0.1 \mathrm{~g} / \mathrm{kg} / \mathrm{b} . \mathrm{w}$, orally for one month; late adult control group: age approximately 18 months, body mass $290 \pm 28 \mathrm{~g}, \mathrm{n}=6$; late adult NS-treated group: age approximately 18 months, body mass $285 \pm 34 \mathrm{~g}, \mathrm{n}=6$; NS was given at a daily dose of $0.1 \mathrm{~g} / \mathrm{kg} / \mathrm{b} . \mathrm{w}$. orally for one month; senile group: the age of rats was approximately 22 months, body mass $230 \pm 22 \mathrm{~g}$, $\mathrm{n}=6$.

Tissue sampling. At the end of the experiment, the rats were euthanized by putting each rat in a conical flask for a few minutes with a piece of cotton that was soaked in $1.9 \%$ ether. Blood samples were taken by cardiac puncture and allowed to clot. Serum samples were used for biochemical analyses.

The thyroid gland was dissected and fixed immediately in $10 \%$ formalin saline. To randomize selection, entire thyroids were cut starting at the superior border, every tenth section (5 $\mu \mathrm{m}$ thick) was put aside for staining [21].

Light microscopic study. The sections were stained with hematoxylin and eosin (H\&E) and Masson's trichrome staining. The stained sections were examined and photographed using a Canon digital camera (Canon, Tokyo, Japan) connected to an IBM computer system.

Immunohistochemistry. Paraffin sections were dewaxed, dehydrated and incubated with $3 \%$ hydrogen peroxide solution for $30 \mathrm{~min}$ at room temperature (RT) and endogenous peroxidase activity was blocked by treatment with $0.9 \%$ hydrogen peroxide in absolute methanol for $10 \mathrm{~min}$. Then, the sections were washed with distilled water; a microwave was utilized for tissue antigen retrieval with sodium citrate buffer solution $(\mathrm{pH}=6)$. Thereafter, sections were washed with distilled water, and placed into phosphate-buffered saline (PBS) for $5 \mathrm{~min}$. After PBS was wiped off, $5 \%$ normal goat serum was added onto the section at RT for $30 \mathrm{~min}$.

Deparaffinized sections of the thyroid were incubated for 30 min at RT with vimentin mouse monoclonal antibody (V9) (\#:MA5-11883 dilution 1:100) and anti-pan cytokeratin (anti-CK AE1/AE3) (\#:MA5-13156 dilution 1:100).
Antibodies were obtained from Thermo Fisher Scientific Industries (Waltham, MA, USA).

Avidin-biotin immunoperoxidase technique was applied in which a biotinylated secondary antibody reacts with peroxidase-conjugated streptavidin molecules. Color reaction was obtained by using diaminobenzidine (DAB) [22]. Negative control sections were performed with the same procedure as mentioned before except that the primary antibody was replaced by non-immune mouse serum.

Histomorphometric study. The quantitative study was performed with Leica Image analysis computer system controlled by Leica Quin 500 software (Leica Imaging System Ltd., Cambridge, UK). Specimen preparations of the thyroid gland, from each rat, were subjected to quantitative studies in 10 non-overlapping microscopic fields picked randomly from each slide. Four sections were analyzed for one thyroid gland with an interval of $1 \mathrm{~mm}$ between the sections to avoid counting of the same follicle. This technique was applied to the thyroid of each rat in a given group, i.e. 24 measurements were taken from each rat group.

The sections were examined within the standard measuring frame of a known area equal to $11694.91 \mu \mathrm{m}^{2}$. The following parameters were measured: (i) the number of follicular cells; (ii) the percentage area of collagen as visualized by Masson's trichrome staining; (iii) the percentage area of vimentin and cytokeratin filaments present in thyroid cells.

\section{Biochemical assays}

Serum concentrations of TSH and thyroid hormones. T3, T4 and TSH concentrations were measured by radioimmunoassay in serum samples using Amersham Test Kits No. 74 and 80 (Amersham International, Amersham, UK).

Oxidative/ antioxidative markers. Protein concentration in the homogenates that were prepared as described below was assessed by the biuret method [23]. $1.0 \mathrm{ml}$ of the homogenates was mixed with $3.0 \mathrm{ml}$ of biuret reagent which gives a blue colored complex. After incubation for $10 \mathrm{~min}$ at $37^{\circ} \mathrm{C}$ absorbance was measured at $540 \mathrm{~nm}$.

Malondialdehyde (MDA), an oxidative stress marker, was measured according to Tipple and Rogers [24]. $100 \mathrm{mg}$ of thyroid tissue was homogenized in $1 \mathrm{~mL}$ of PBS, $\mathrm{pH} 7.0$ with a micropestle in a microtube. $20 \%$ trichloric acid solution was added to the thyroid tissue homogenate to precipitate the protein, and centrifuged. $0.8 \%$ thiobarbituric acid (TBA) solution was added to the supernatants. After boiling for $10 \mathrm{~min}$ in a water bath the absorbance was measured at $405 \mathrm{~nm}$. The concentration of MDA was calculated using the standard curve and expressed per mg of protein.

Tissue glutathione (GSH) content was measured according to Tipple and Rogers [24]. The measurement was based on the reduction of 5, 5-dithiobis-(2-nitrobenzoic acid) (DTNB) with reduced glutathione to produce a yellow com- 
Table 1. Primer sequences of the VEGF and beta-actin

\begin{tabular}{|l|c|c|}
\hline Isoform & Sense primer & Anti-sense primer \\
\hline VEGF & GCA CTG GAC CCT GGC TTT ACT & ATG GGA CTT CTG CTC TCC TTC TG \\
\hline Beta-Actin & ATC TGG CAC CAC ACC TTC & AGC CAG GTC CAG ACG CA \\
\hline
\end{tabular}

pound. The reduced chromogen was directly proportional to GSH concentration and its absorbance was measured at $405 \mathrm{~nm}$ by using a commercial kit (Biodiagnostic, Cairo, Egypt). Concentration of MDA was calculated using standard curve and expressed per mg of protein.

The superoxide dismutase (SOD) activity in tissue homogenate was measured according to Weydert and Cullen [25] by the inhibition of nitroblue tetrazolium reduction by $\mathrm{O}_{2}$-generated by the xanthine/xanthine oxidase system. One unit is the amount of SOD that inhibits the rate of formazan dye formation by $50 \%$.

\section{Evaluation of VEGF gene expression by real time PCR} Total RNA extraction. Total RNA was extracted from the thyroid tissue using the TRIzol method according to the manufacturer's protocol (Invitrogen, Life Technologies, Waltham, MA, USA). In brief, RNA was extracted by homogenization in TRIzol reagent. The homogenate was then incubated for $5 \mathrm{~min}$ at RT. A 1:5 volume of chloroform was added, and the tube was vortexed and centrifuged at $12,000 \mathrm{~g}$ for $15 \mathrm{~min}$. Thereafter, aqueous phase was isolated, and the total RNA was precipitated with absolute ethanol. After centrifugation and washing, total RNA was finally diluted in $20 \mu \mathrm{L}$ of RNase-free water. RNA concentrations and purity were measured with an ultraviolet spectrophotometer at $260 \mathrm{~nm}$.

Complementary DNA (cDNA) synthesis. cDNA was synthesized from $1 \mu \mathrm{g}$ RNA using Superscript III First-Strand Synthesis as described in the manufacturer's protocol (Invitrogen, Life Technologies). In brief, $1 \mu \mathrm{g}$ of total RNA was mixed with $50 \mu \mathrm{M}$ oligo(DT) $20,50 \mathrm{ng} / \mu \mathrm{L}$ random primers, and $10 \mathrm{mM}$ dNTP mix in a total volume of $10 \mu \mathrm{L}$. The mixture was incubated at $56^{\circ} \mathrm{C}$ for $5 \mathrm{~min}$ and then placed on ice for $3 \mathrm{~min}$.

Reverse transcriptase master mix containing $2 \mu \mathrm{L}$ of 10 $\times \mathrm{RT}$ buffer, $4 \mu \mathrm{L}$ of $25 \mathrm{mM} \mathrm{MgCl} 2,2 \mu \mathrm{L}$ of $0.1 \mathrm{M}$ DTT, and $1 \mu \mathrm{L}$ of SuperScript ${ }^{\circledR}$ III RT $(200 \mathrm{U} / \mu \mathrm{L})$ was added to the mixture and was incubated at $25^{\circ} \mathrm{C}$ for $10 \mathrm{~min}$ followed by $50 \mathrm{~min}$ at $50^{\circ} \mathrm{C}$.

Real-time quantitative PCR. Relative abundance of mRNA species was assessed using the SYBR Green method on an ABI prism 7500 sequence detector system (Applied Biosystems, Foster City, CA, USA). PCR primers (shown in Table 1) were designed with Gene Runner Software (Hasting Software, Inc., Hasting, NY, USA) from RNA sequences from Gen Bank. All primer sets had a calculated annealing temperature of $60^{\circ}$. Quantitative RT-PCR was performed in a 25- $\mu$ l reaction volume consisting of $2 X$ SYBR Green PCR Master Mix (Applied Biosystems), $900 \mathrm{nM}$ of each primer and 2-3 $\mu \mathrm{L}$ of cDNA. Amplification conditions were $2 \mathrm{~min}$ at $50^{\circ}, 10 \mathrm{~min}$ at $95^{\circ}$ and 40 cycles of denaturation for $15 \mathrm{~s}$ and annealing/extension at $60^{\circ}$ for $10 \mathrm{~min}$. Data from real-time assays were calculated using the v1.7 Sequence Detection Software from PE Biosystems (Foster City, CA, USA). Relative expression of studied gene mRNA was calculated using comparative $\mathrm{Ct}$ method. All values were normalized to beta actin gene and reported as fold change over control group.

Statistical analysis. Statistical analysis was performed using statistical package for the social sciences (SPSS) version 21.0 (IBM Corporation, Somers, NY, USA) statistical software. Data were expressed as means \pm standard deviation (SD). Statistical evaluation was done using one-way analysis of variance (ANOVA) followed by Bonferroni pairwise comparisons. Significance was considered when the $\mathrm{p}$ value was less than 0.05 .

The percentage of increase or decrease (difference) in all study parameters were calculated with the following formula: Percentage of difference $=($ Mean difference value between two groups $) /($ Value of the compared group $) \times 100$.

\section{Results}

\section{Morphology of the thyroid gland of rats of various ages assessed by light microscopy}

\section{The structure of the thyroid gland as revealed \\ by $H \& E$ staining}

Thyroid follicles in the young adult control and young adult NS-treated rats were lined with one layer of simple cuboidal epithelium and were filled with homogeneous colloid (Fig. 1A, B). On the contrary, follicles in the late adult control group were dilated and disrupted. Few follicular cells showed cytoplasmic vacuoles (Fig. 1C). Marked improvement of the follicle morphology was observed in the late adult NS-treated group. The follicles had regular shape and were lined with a layer of simple cuboidal epithelium, cells sometimes showed vacuolation (Fig. 1D). Finally, follicles in the senile group were irregular with cellular exfoliation. Many follicles were dilated and lined with flattened cells. Some follicles were empty, while 

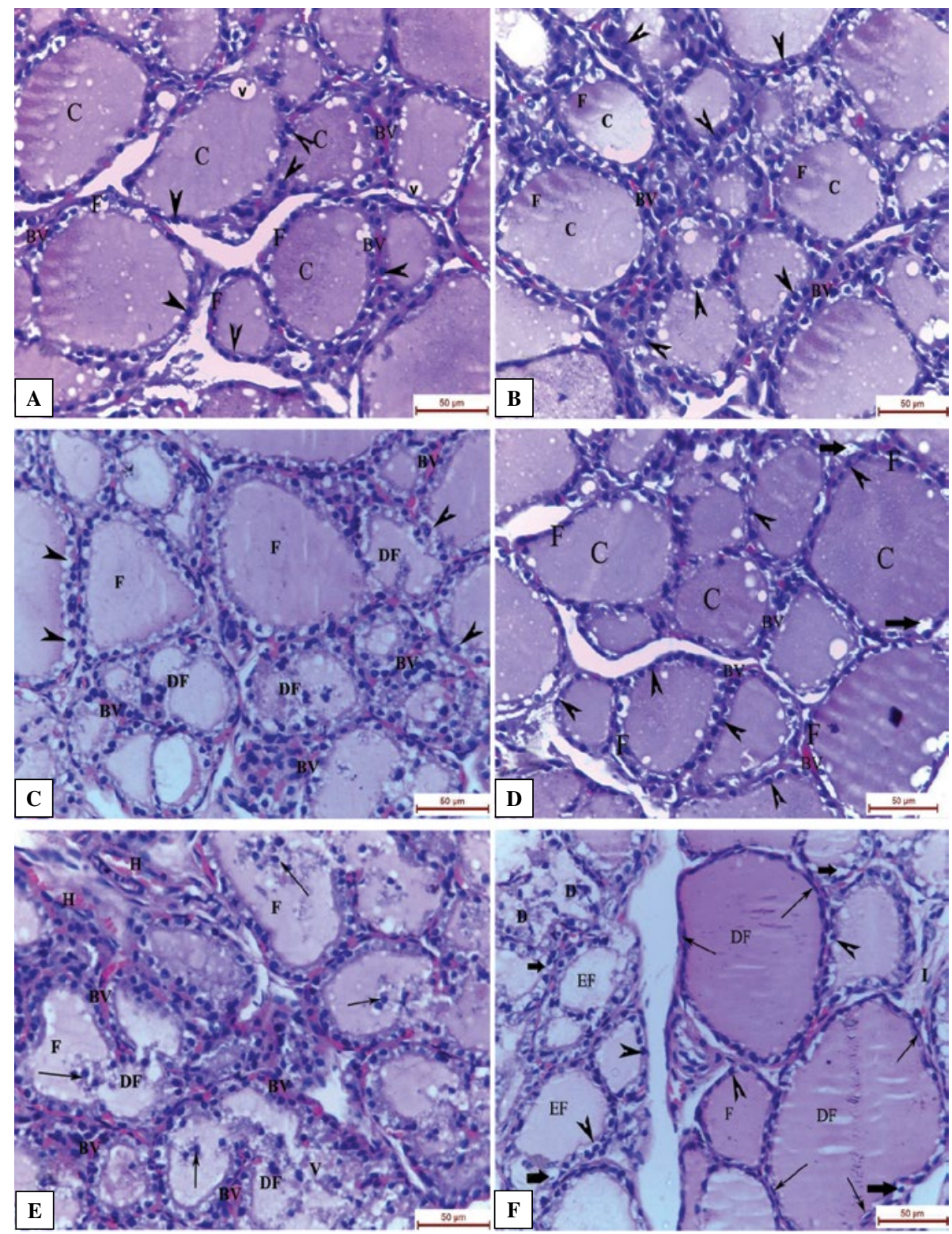

Figure 1. Thyroid gland morphology in different age groups of control and Nigella sativa oil-treated rats. (A) Young control rat (7 months), and (B) young adult NS-treated rat: follicles (F) lined with simple cuboidal epithelium (arrowheads) contain colloid (C) with some vacuoles (V); note blood vessels (BV) between the follicles. (C) Late adult control rat (18 months): dilated follicles (F) and disrupted follicles (DF). Note blood vessels (BV) and follicular cells (arrowheads). (D) Late adult NS-treated rat: Regular follicles lined with a layer of simple cuboidal epithelium (arrowheads) and filled with restored colloid (C). Note blood vessels (BV) and vacuolated cells (arrows). (E and F) Senile rats (22 months): irregular follicles (F) with exfoliated cells (arrows) and disrupted follicles (DF) that fuse with other follicles. Note increased number of blood vessels (BV) between the follicles with blood extravasation (H) and dilated follicles (DF) lined with flattened cells (arrows). Some follicles are empty (EF), while others are disrupted (DF). Note increased interstitial connective tissue content (I). Hematoxylin and eosin staining. Scale bars $50 \mu \mathrm{m}$, total magnification $200 \times$.

others were disrupted. Increased presence of blood vessels between the follicles with blood extravasation was also observed (Fig. 1E, F).

The histomorphometry of the thyroid glands revealed that the mean number of follicular cells in the late adult control and senile groups decreased by $34 \%$ and $46 \%$, respectively, compared to the young adult control group (Table 2). Administration of NS oil to late adult rats significantly increased the number of thyrocytes as compared to control rats of the same 
Table 2. Histomorphometric analysis of the number of follicular cells and area percentage of collagen fibers, cytokeratin and vimentin filaments in the thyroid of rats of different ages

\begin{tabular}{|l|c|c|c|c|}
\hline Groups & Number of follicular cells & Area \% of collagen fibers & Area \% of cytokeratin & Area \% of vimentin \\
\hline Young adult control group & $33.40 \pm 2.27^{*, \#, s, \&}$ & $1.77 \pm 0.82$ & $0.74 \pm 0.34^{\$, \&}$ & $2.65 \pm 0.26^{*, \&}$ \\
\hline Young adult NS-treated group & $39.20 \pm 1.81^{+, \#, s, \&}$ & $1.16 \pm 0.34^{\#, \&}$ & $0.54 \pm 0.25^{\#, s, \&}$ & $0.94 \pm 0.34^{+, \#, \$, \&}$ \\
\hline Late adult control group & $22.00 \pm 1.49^{+, *, \$, \&}$ & $3.94 \pm 0.82^{+, *, \&}$ & $3.08 \pm 0.65^{+, *, \&}$ & $4.78 \pm 0.53^{+, *, \$, \&}$ \\
\hline Late adult NS-treated group & $28.20 \pm 1.81^{+, *, \#, \&}$ & $1.64 \pm 0.70^{\#, \&}$ & $1.64 \pm 0.30^{+, *, \#, \&}$ & $3.16 \pm 0.51^{*, \#, \&}$ \\
\hline Senile group & $18.00 \pm 1.49^{+, *, \#, \$}$ & $6.18 \pm 1.01^{+, *, \#, \$}$ & $5.76 \pm 0.54^{+, *, \#, \$}$ & $6.16 \pm 0.36^{+, *, \#, \$}$ \\
\hline
\end{tabular}

Data are presented as mean \pm SD. ${ }^{+}$significant difference $v s$ young adult control group; * significant difference $v s$ young adult NS-treated group; ${ }^{\#}$ significant difference $v s$ late adult control group; ${ }^{\$}$ significant difference $v s$ late adult NS-treated group; ${ }^{\star}$ significant difference $v s$ senile group; all statistical symbols show $\mathrm{p} \leq 0.05$.

age; however, the mean number of follicular cells in this group was still lower than in the young adult control group (Table 2).

The content of connective tissue fibers: qualitative and quantitative study

Collagen fibers visualized by Masson's trichrome staining were present between follicles and blood vessels. Minimal amount of collagen fibers was observed in the young adult control and young adult NS-treated groups. Increased contribution of collagen fibers in the extrafollicular matrix was observed in the late adult control and senile groups. This increase was ameliorated in the thyroids of late adult rats treated with NS oil (Fig. 2).

Mean area percent of collagen fibers increased with aging. Compared to that of the young adult control group, it became 1.2-fold higher in the late adult control group and doubled in the senile group (2.4-fold higher). However, a 58\% significant decrease in the presence of collagen fibers was noted in the late adult NS-treated group as compared to that of the late adult control group suggesting an improvement with the use of NS. Moreover, the area percent in the late adult NS-treated group reached that of the young adult control group (Table 2).

\section{Immunoreactivity of vimentin and cytokeratin filaments in the thyroid gland: qualitative and quantitative study}

Minimal immunoreactivity of vimentin filaments was seen in the fibroblasts and wall of blood vessels of young adult control and young adult NS-treated rats (Fig. 3A, B). Increased immunoreactivity was observed in the late adult control and senile groups (Fig. 3C, E). Immunoreactivity was found to be very weak in the late adult NS-treated group (Fig. 3D).

Immunoreactivity of cytokeratin in the interstitial tissue was minimal in the young adult control and young adult NS-treated rats (Fig. 4A, B). Immunoreactivity increased in the late adult control and senile groups (Fig. 4C, E). The reactivity became minimal in the late adult NS-treated group (Fig. 4D).

The mean area percent of vimentin filaments increased with aging (Table 2). It increased in the late adult control group up to $80 \%$ of that of the young adult control group. With the advancement of age, in the senile group it became 1.3-fold higher than that of the young adult control group. On the contrary, the area percent in the late adult NS-treated group revealed a $33 \%$ significant decrease as compared to that of the late adult control group; however, it did not reach the level of the young adult control group (Table 2).

Mean area percent of cytokeratin filaments increased with the advancement of age (Table 2). Compared to that of the young adult control group, it became 3.2-fold higher in the late adult control group and this value doubled in the senile group to become 6.7-fold higher. However, a 47\% significant decrease in the area percent of cytokeratin filaments was noted in the late adult NS-treated group as compared to that of the late adult control group; however, it did not reach that of the young adult control group (Table 2).

\section{TSH and thyroid hormone serum concentrations}

Compared to the young adult control group, mean value of serum $\mathrm{T} 3$ in both late adult control and senile groups were $28 \%$ and $33 \%$ lower and mean values of T4 in these groups were $6 \%$ and $13 \%$ lower. Mean value of T3 in the late adult NS-treated group compared to that of the late adult control group was $28 \%$ higher; however, it did not reach the value of the young adult control group (Table 3).

Mean TSH values in the late adult control and senile groups revealed 1.2- and 2.9-fold increments compared with that of the young adult control group. 


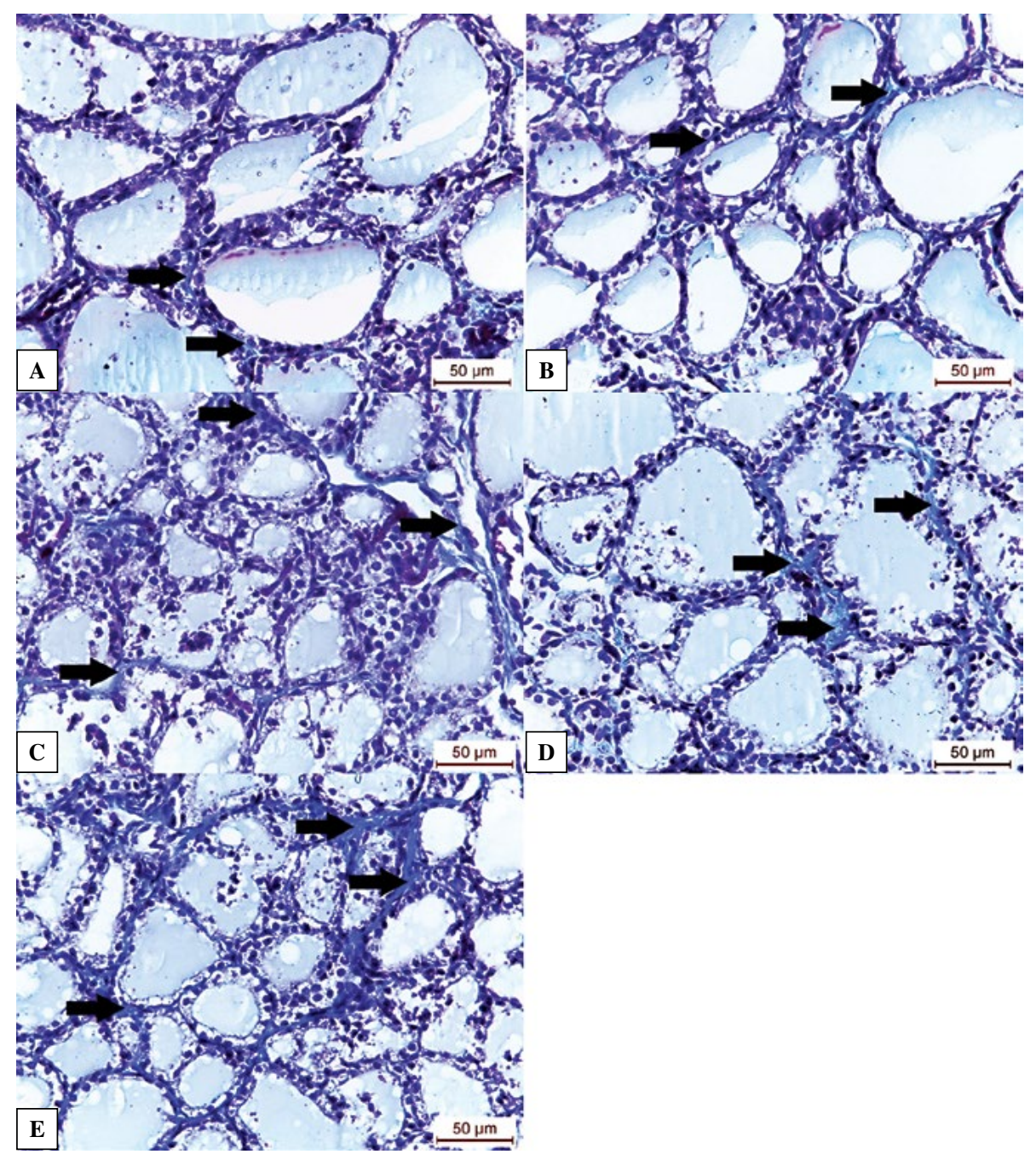

Figure 2. Collagen presence in the thyroids of rats of different age groups including those treated with Nigella sativa oil. (A) young adult control group (age 7 months); (B) young adult NS-treated group (age 7 months); (C) late adult control group (age 18 months); (D) late adult NS-treated group: (age 18 months); E. Senile group (age 22 months). A, B. Minimal distribution of collagen fibers in the thyroids of young rats; $\mathbf{C}$. Increased distribution of collagen fibers in a late adult control rat; D. Minimal distribution of collagen fibers in a late adult NS-treated rat; E. Marked increase in collagen fibers content in a thyroid of a senile rat. Masson's trichrome staining. Scale bars $50 \mu \mathrm{m}$, total magnification $400 \times$.

Mean value of TSH in the late adult NS-treated group was $35 \%$ lower than that of the late adult control group; however, it did not reach that of the young adult control group ( $42 \%$ higher).

\section{Markers of oxidative stress in the thyroids of rats of increasing age}

Mean values of MDA content in the late adult control and senile groups were 3.2-and 4.5-fold higher than that of the young adult control group, respectively. MDA level of the late adult NS-treated group was $27 \%$ lower than that of the late adult control group; however, it did not reach that of the young adult control group that was 2-fold higher (Table 4).
Compared with the young adult control group, the mean values of SOD in the late adult control and senile groups were $45 \%$ and $49 \%$ lower and the mean values of GSH in these groups were $36 \%$ and $46 \%$ lower (Table 4).

\section{Expression of the VEGF gene in the rat thyroid}

Mean values of VEGF in the late adult control and senile groups showed 1.1- and 2.4-fold increases when compared to that of the young adult control group. Much improvement was observed with the use of the NS as mean values in the late adult NS-treated group revealed a $36 \%$ decrease as compared to that of the late adult control group (Table 4). 


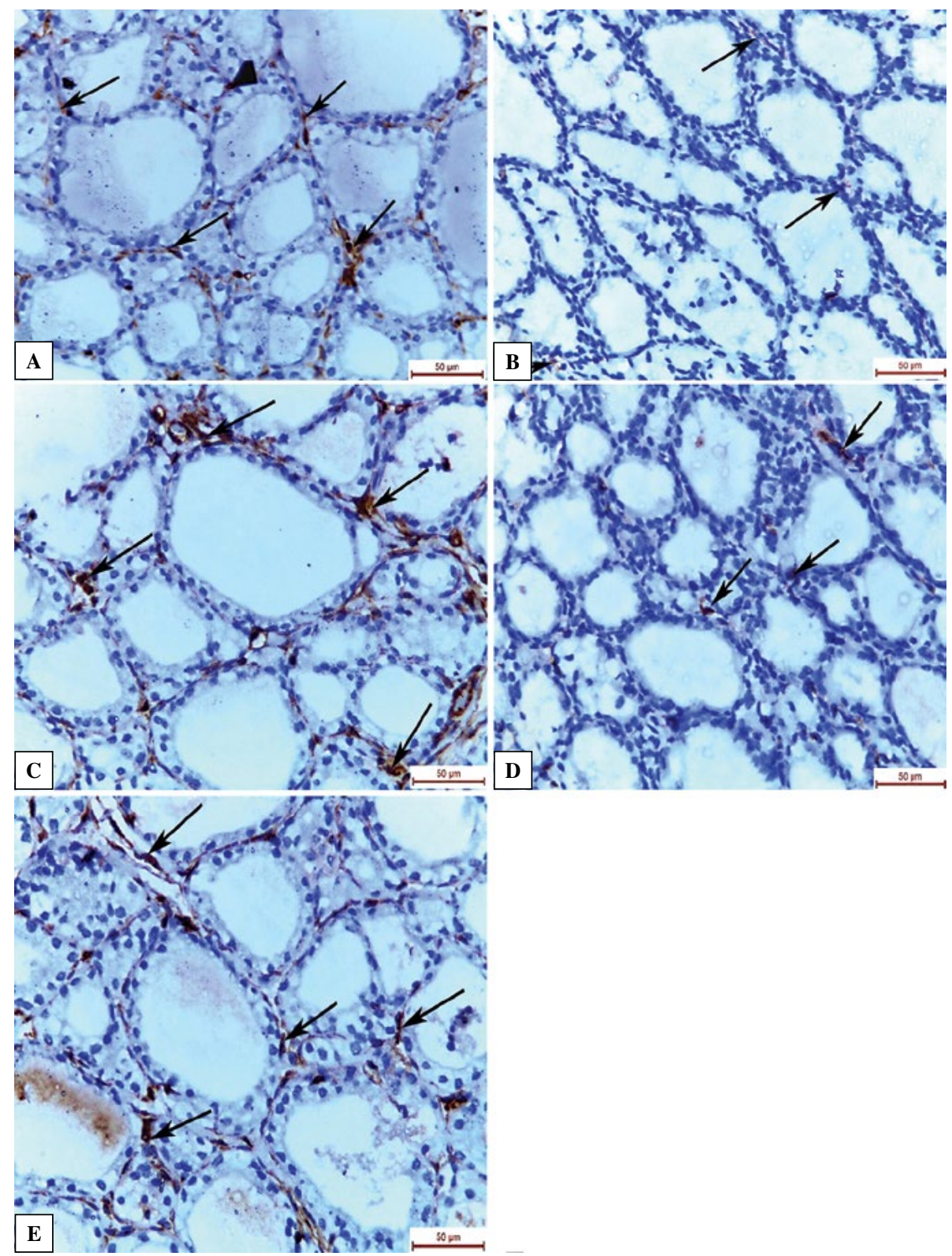

Figure 3. Vimentin immunoreactivity in fibroblasts and wall of blood vessels (arrows) in the different age groups of rat and rats treated with Nigella sativa oil. (A-E) age and experimental groups of rats as in the description of Figure 2. A, B. Minimal immunoreactivity in the young adult control and young adult NS-treated rats; C. Increased immunoreactivity a late adult control rat; D. Minimal immunoreactivity in a late adult NS-treated rat. E. Intense immunoreactivity in a senile rat. Immunohistochemical visualization of vimentin was performed as described in Methods. Scale bars $50 \mu \mathrm{m}$, total magnification $400 \times$.

\section{Correlations among variables in different groups}

Correlation between TSH \& thyroid hormone levels and follicular cell number

A strong positive correlation was found between the number of follicular cells and T3/T4 levels. On the contrary, a strong negative correlation was found between the mean number of follicular cells and the TSH levels (Table 5).

\section{Correlation between cytoskeletal intermediate} filaments/VEGF and oxidative/antioxidative markers A strong positive correlation was found between oxidative markers and cytoskeletal intermediate filaments/VEGF. On the contrary, a strong negative correlation was found between antioxidative markers and cytoskeletal intermediate filaments/ /VEGF (Table 6).

Apart from the mean number of follicular cells and area percent of vimentin, there were non-significant 


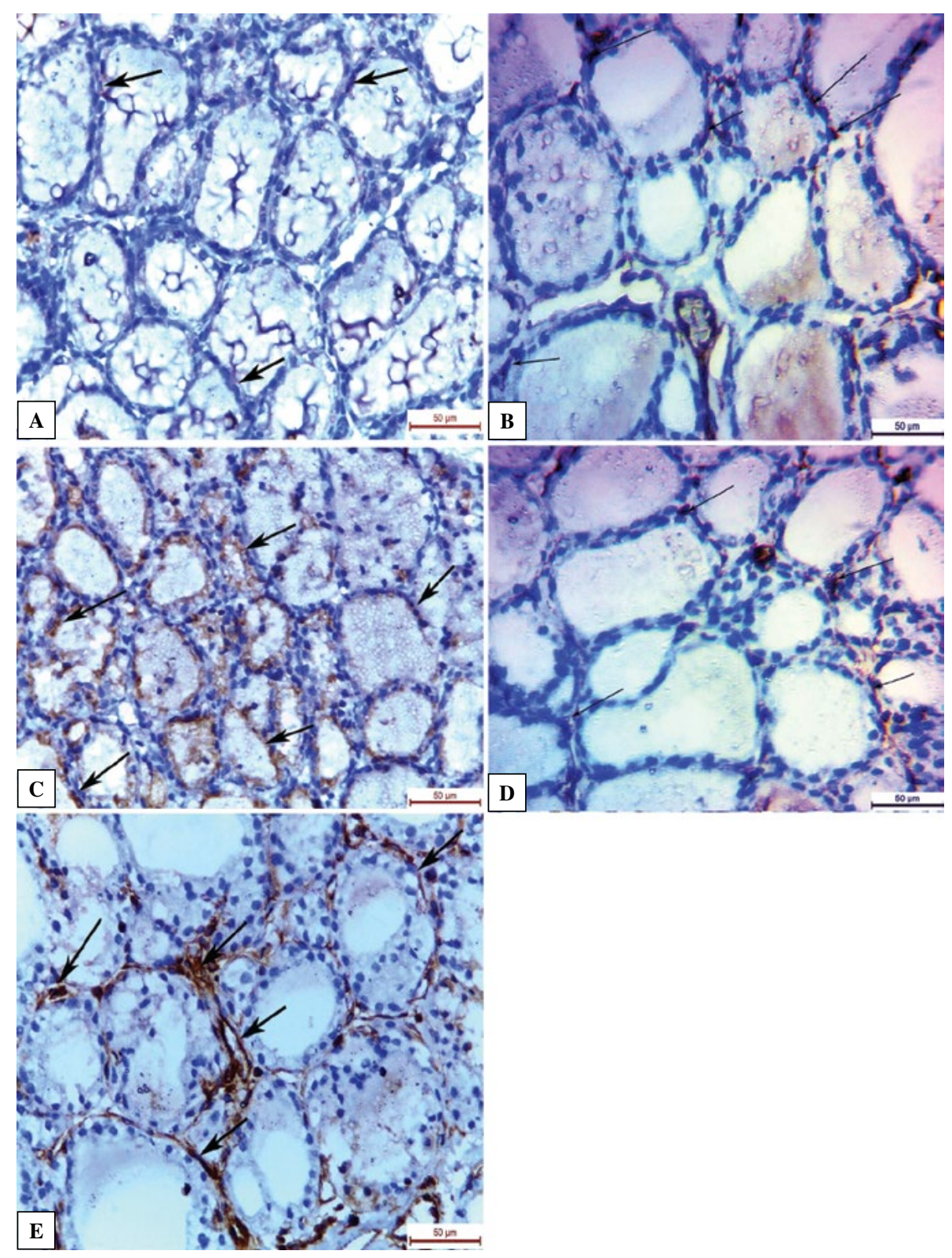

Figure 4. Cytokeratin immunoreactivity in the interstitial tissue (arrows) of rats of the different age groups. (A-E) Age and experimental groups of rats as described for Figure 2. A, B. Mild immunoreactivity; C. Increased cytokeratin immunoexpression in late adult control rat; D. Decreased immunoreactivity as compared with (c); E. Strong immunoreactivity in a senile rat. The immunohistochemical visualization of cytokeratin was performed as described in Methods. Scale bars $50 \mu \mathrm{m}$, total magnification $400 \times$.

differences between the young adult control and young adult NS-treated groups. The young adult NS-treated group displayed a significant increase in the number of follicular cells, while the area percent of vimentin exhibited a significant decrease (Table 2, Fig 3).

\section{Discussion}

The world's population over 60 is growing quickly and will reach $22 \%$ of the global population in the next years [26]. Aging process is highly intricate; it leads to gradual deterioration in physiological functions, including the endocrine system, which may be responsible for gradual increase in morbidity and mortality.

Follicles in the young adult control group were lined with a single layer of cuboidal epithelium. With aging, follicles in the late adult control and senile groups became irregular and dilated. Their lining was converted into simple squamous flattened cells. Similar findings were reported in dogs [27]. These 
Table 3. TSH and thyroid hormone serum levels in the different rat groups

\begin{tabular}{|l|c|c|c|}
\hline Groups & $\mathbf{T 3}[\mathbf{n g} / \mathbf{d l}]$ & $\mathbf{T 4}[\boldsymbol{\mu g} / \mathbf{d l}]$ & TSH $[\mathbf{m I U} / \mathbf{L}]$ \\
\hline Young adult control group & $127.16 \pm 8.52^{\#, \$, \&}$ & $4.14 \pm 0.20^{\#, \&}$ & $13.34 \pm 1.67^{\#, \$, \&}$ \\
\hline Young adult NS-treated group & $134.30 \pm 10.40^{\#, s, \&}$ & $4.25 \pm 0.22^{\# . \&}$ & $12.17 \pm 1.71^{\#, \$, \&}$ \\
\hline Late adult control group & $90.90 \pm 5.07^{+, *, \$}$ & $3.87 \pm 0.23^{+, *, \&}$ & $29.42 \pm 6.21^{+, *, \$, \&}$ \\
\hline Late adult NS-treated group & $116.46 \pm 5.43^{+, *, \#, \&}$ & $4.07 \pm 0.09^{\&}$ & $18.98 \pm 2.57^{+, *, \#, \&}$ \\
\hline Senile group & $84.91 \pm 4.50^{+, *, \$}$ & $3.60 \pm 0.23^{+, *, \#, \$}$ & $51.85 \pm 4.26^{+, *, \#, \$}$ \\
\hline
\end{tabular}

Data are presented as mean \pm SD. Meaning of statistical symbols are the same as described for Table 2 and all represent $\mathrm{p} \leq 0.05$.

Table 4. Levels of oxidative/antioxidative markers and VEGF gene expression in the thyroids of different rat age groups

\begin{tabular}{|l|c|c|c|c|}
\hline Group & MDA [nmol/mg] & SOD $[\mathbf{U} / \mathbf{m g}]$ & GSH $[\mathbf{m m o l} / \mathbf{m g}]$ & VEGF mRNA (fold change) \\
\hline Young adult control group & $1.19 \pm 0.38^{\#, \$, \&}$ & $3.75 \pm 1.11^{\#, \&}$ & $59.03 \pm 3.12^{\#, \$, \&}$ & $1.74 \pm 0.43^{\$, \&}$ \\
\hline Young adult NS-treated group & $0.96 \pm 0.32^{\#, \$, \&}$ & $4.69 \pm 1.77^{\#, \$, \&}$ & $60.80 \pm 4.98^{\#, \$, \&}$ & $1.80 \pm 0.54^{\$, \&}$ \\
\hline Late adult control group & $5.02 \pm 0.52^{+, *, \$, \&}$ & $2.05 \pm 0.28^{+, *}$ & $37.53 \pm 2.65^{+, *}$ & $3.72 \pm 0.53^{+, *, \$, \&}$ \\
\hline Late adult NS-treated group & $3.62 \pm 0.67^{+, *, \#, \&}$ & $2.74 \pm 0.37^{*, \&}$ & $44.41 \pm 4.58^{+, *, \& \%}$ & $2.38 \pm 0.40^{\#, \&}$ \\
\hline Senile group & $6.62 \pm 0.96^{+, *, \#, \$}$ & $1.89 \pm 0.67^{+, *}$ & $31.76 \pm 9.43^{+, *, \$}$ & $5.90 \pm 0.70^{+, *, \#, \$}$ \\
\hline
\end{tabular}

Values are expressed per mg proteins. Data are presented as mean \pm SD. Meaning of statistical symbols are the same as described for Table 2 and all represent $\mathrm{p} \leq 0.05$.

Table 5. Correlation between T3, T4, TSH and follicular cell number

\begin{tabular}{|l|c|}
\hline & Number of follicular cells \\
\hline T3 [ng/dl] & $0.902^{*}$ \\
Pearson Correlation & 0.000 \\
Sig. (2-tailed) & \\
\hline T4 [ $\mu$ g/dl] & $0.724^{*}$ \\
Pearson Correlation & 0.000 \\
Sig. (2-tailed) & \\
\hline TSH & $-0.856^{*}$ \\
Pearson Correlation & 0.000 \\
Sig. (2-tailed) & \\
\hline
\end{tabular}

*Significant $\mathrm{p}$ value using Pearson correlation

histological changes might be due to distension of the lumen with colloid. The increase in intrafollicular colloid content and decreased endocytotic activity of follicular cells may contribute to the age-associated flattening of follicular epithelium [28].

The thyroids of the studied young, adult, senile and NS-treated rats revealed follicles of a variable size. In the young adult control group, follicles were small to medium. The larger follicles tended to be more in the periphery. This type of follicular distribution is called zonal variation in follicular size. Bocian-Sobkowska et al. estimated this zonal variation and found the ratio of the central zone follicles to the peripheral zone follicles to be 1:2 [29]. These zonal variations might be explained by the tendency of the central follicles to be more active than the peripheral one.

Zonal variation was absent in the thyroids of the late adult control and senile rats. Follicles were dilated and disrupted in considerable portions of the gland. These findings are similar to those of other authors [30]. Follicular disruption observed in our study in the thyroids of aged rats may result in a follicular fusion, and, hence, the emergence of dilated large follicles.

Some follicles in the young adult control group were filled with vacuolated colloid. These vacuolations reflect the endocytotic activity of thyrocytes during thyroid hormones' release [3]. In the thyroids of late adult control and senile rats, many follicles were devoid of the colloid which is a distinctive sign of inactive follicles [30].

Late adult control and senile rats exhibited a significant reduction in the mean number of follicular cells when compared to that of young adult control animals. Positive correlation was found between the number of follicular cells and T3 and T4 serum levels. The decrease in the T3 and T4 levels is the direct outcome of the decrease in the follicular cell number. The degenerative changes of the thyroid gland of aged Sprague-Dawley rats with concomitant decrease in the glandular function were reported earlier [6]. 
Table 6. Correlations between cytoskeletal intermediate filaments/VEGF and oxidative/antioxidative markers

\begin{tabular}{|l|c|c|c|}
\hline & Area \% of cytokeratin & Area \% of vimentin & VEGF mRNA levels \\
\hline MDA [nmol/mg] & & & $0.905^{*}$ \\
Pearson Correlation & $0.904^{*}$ & $0.875^{*}$ & 0.000 \\
Sig. (2-tailed) & 0.000 & 0.000 & $-0.659^{*}$ \\
\hline SOD [U/mg] & & & 0.000 \\
Pearson Correlation & $-0.621^{*}$ & $-0.562^{*}$ & $-0.840^{*}$ \\
Sig. (2-tailed) & 0.000 & 0.000 & 0.000 \\
\hline GSH [mmol/mg] & & & $-0.798^{*}$ \\
Pearson Correlation & $-0.822^{* *}$ & 0.000 & \\
Sig. (2-tailed) & 0.000 & & \\
\hline
\end{tabular}

* Significant $\mathrm{p}$ value using the Pearson correlation

On the contrary, serum level of TSH exhibited a significant increase in the late adult control and senile rats. In addition, a negative correlation was found between the mean number of follicular cells and TSH levels. Thus, aging did not suppress the function of the pituitary-thyroid feedback mechanism since the decrement in serum T3 and T4 levels in the late adult control and senile rats was associated with increased TSH levels [31].

A significant increment in the mean area percent of collagen was a distinctive sign in the structure of the thyroid of late adult and senile rats. Connective tissue could replace destroyed structures and degenerated follicles that more often occur in aging [6].

Several mechanisms of aging process were suggested, including the free-radical theory of aging proposed by Denham Harman [32]. Accumulation of free radicals produced by energetic metabolism of the mitochondria causes cellular toxicity and produces damage to the nuclear and mitochondrial DNA and also to the cellular membrane structures. A clear shift of the oxidative/antioxidative markers (MDA/GSH, SOD) was observed in the late adult control and senile rat groups in favor of oxidants what suggests that thyroid aging is associated with stress [33].

Immunoreactivity of the cytoskeletal intermediate filaments (vimentin and cytokeratin) was high in the thyroids of late adult control and senile groups. Vimentin presence was observed in the fibroblasts and in the wall of blood vessels, while cytokeratin reaction was observed in the interstitial tissue. Intermediate filaments were shown to be greatly affected by oxidative stress in the hippocampus of rats [34]. We found a positive correlation between increased expression of the cytoskeletal intermediate filaments and increment of oxidative stress marker MDA in the thyroids of late adult control and senile groups.
On the contrary, a negative correlation between the expression of intermediate filaments and antioxidative markers (GSH, SOD) was observed in the thyroids of rats of the same age groups.

The young adult control and young adult NS-treated groups displayed low VEGF mRNA levels as this factor is normally released in minimal amounts in normal thyroid cells [35]. The high increase in the contents of blood vessels in thyroids of late adult control and senile rats might have been caused by increased expression of the VEGF gene that promotes angiogenesis [16] or by increased serum TSH levels that trigger thyroid angiogenesis [36]. Increase in the level of VEGF mRNA in the thyroids of late adult and senile rats might have been induced by age-related increased oxidative stress [37]. This assumption is supported by our finding of a positive correlation between increased level of VEGF and increased content of the oxidative stress marker MDA and a negative correlation between the level of VEGF mRNA and the amount of antioxidative markers (GSH, SOD) in late adult and senile control rats.

It has been widely assumed that antioxidants can handicap the oxidation of various macromolecules such as DNA and proteins, thus interfering with the aging process and increasing the lifespan of animals [38]. The evident role of Nigella sativa in the amelioration of the age-related alterations in the structure and function of the rat thyroid gland might be attributed to a high content of thymoquinone (TQ), one of the main components of the NS oil that has a strong antioxidant effect [39].

The thyroids of late adult NS-treated group presented follicles lined with cuboidal epithelium and contained regularly the restored colloid with signs of endocytic activity. The latter phenomenon observed in late adult rats treated with NS oil might be attrib- 
uted to a significant increase in the mean number of follicular cells since a positive correlation was found between the number of follicular cells and T3 and T4 levels. Moreover, similarly as in the elderly [31], in this experimental group the pituitary-thyroid feedback mechanism was well preserved since the rats displayed decreased TSH levels. In addition, a significant decrement in the mean area percent of collagen fibers was detected in that group.

The age-related increase in oxidative stress in the thyroids of rats was almost abolished after NS oil supplementation in late adult rats: the MDA level decreased significantly, while SOD and GSH levels revealed a noticeable rise. Such findings suggest that NS and its metabolites act as radical scavengers by suppressing oxidative stress [40].

Immunoreactivity of cytoskeletal intermediate filaments (vimentin and cytokeratins) displayed significant reductions in the thyroids of late adult NS-treated rats. This might be attributed to thymoquinone, the component of the NS oil, which has a strong antioxidant effect [39] and was shown to abolish experimentally-induced circulatory oxidative stress [19]. Moreover, thymoquinone may be responsible for the significant reduction of the VEGF mRNA levels in the thyroids of late adult NS-treated rats since it was shown to inhibit angiogenesis [41].

In summary, we have demonstrated that aging induces alterations in both structure and function of the rat thyroid gland mostly through the increase in oxidative stress, and their abolishment by the treatment of rats with Nigella sativa oil may be attributed to its antioxidative properties.

\section{Conflicts of interest: none}

\section{References}

1. López-Otín C, Blasco MA, Partridge L, et al. The hallmarks of aging. Cell. 2013; 153(6): 1194-1217, doi: 10.1016/j. cell.2013.05.039, indexed in Pubmed: 23746838.

2. Ruetenik A, Barrientos A. Dietary restriction, mitochondrial function and aging: from yeast to humans. Biochim Biophys Acta. 2015; 1847(11): 1434-1447, doi: 10.1016/j. bbabio.2015.05.005, indexed in Pubmed: 25979234.

3. da Costa VM, Rosenthal D. Effects of aging on thyroidal function and proliferation. Curr Aging Sci. 2008; 1(2): 101-104, indexed in Pubmed: 20021378.

4. Sultana SZ, Khan MK, Sultana S, et al. Histomorphometric study of thyroid gland of Bangladeshi people. Mymensingh Med J. 2007; 16(1): 36-42, indexed in Pubmed: 17344778.

5. Faggiano A, Coulot J, Bellon N, et al. Age-dependent variation of follicular size and expression of iodine transporters in human thyroid tissue. J Nucl Med. 2004; 45(2): 232-237, indexed in Pubmed: 14960641.

6. Rao-Rupanagudi S, Heywood R, Gopinath C. Age-related changes in thyroid structure and function in Sprague-
-Dawley rats. Vet Pathol. 1992;29(4): 278-287, doi: 10.1177/0300 98589202900402, indexed in Pubmed: 1514215.

7. Abdel-Magied EM, Taha AA, Abdalla AB. Light and electron microscopic study of the thyroid gland of the camel (Camelus dromedarius). Anat Histol Embryol. 2000; 29(6): 331-336, indexed in Pubmed: 11199476.

8. Ajish TP, Jayakumar RV. Geriatric thyroidology: An update. Indian J Endocrinol Metab. 2012; 16(4): 542-547, doi: 10.4103/2230-8210.98006, indexed in Pubmed: 22837913.

9. Herrmann H, Bär H, Kreplak L, et al. Intermediate filaments: from cell architecture to nanomechanics. Nat Rev Mol Cell Biol. 2007; 8(7): 562-573, doi: 10.1038/nrm2197, indexed in Pubmed: 17551517.

10. Eriksson JE, Dechat T, Grin B, et al. Introducing intermediate filaments: from discovery to disease. J Clin Invest. 2009; 119(7): 1763-1771, doi: 10.1172/JCI38339, indexed in Pubmed: 19587451.

11. Shin JU, Lee WJ, Oh SHo, et al. Altered vimentin protein expression in human dermal microvascular endothelial cells after ultraviolet or intense pulsed light treatment. Lasers Surg Med. 2014; 46(5): 431-438, doi: 10.1002/lsm.22253, indexed in Pubmed: 24737666.

12. Fonseca E, Nesland JM, Höie J, et al. Pattern of expression of intermediate cytokeratin filaments in the thyroid gland: an immunohistochemical study of simple and stratified epithelial-type cytokeratins. Virchows Arch. 1997; 430(3): 239-245, indexed in Pubmed: 9099982.

13. Pan X, Hobbs RP, Coulombe PA. The expanding significance of keratin intermediate filaments in normal and diseased epithelia. Curr Opin Cell Biol. 2013; 25(1): 47-56, doi: 10.1016/j. ceb.2012.10.018, indexed in Pubmed: 23270662.

14. Palmer BF, Clegg DJ. Oxygen sensing and metabolic homeostasis. Mol Cell Endocrinol. 2014; 397(1-2): 51-58, doi: 10.1016/j.mce.2014.08.001, indexed in Pubmed: 25132648.

15. Malkomes P, Oppermann E, Bechstein WO, et al. Vascular endothelial growth factor--marker for proliferation in thyroid diseases? Exp Clin Endocrinol Diabetes. 2013; 121(1): 6-13, doi: 10.1055/s-0032-1327634, indexed in Pubmed: 23329570.

16. Wang JF, Milosveski V, Schramek C, et al. Presence and possible role of vascular endothelial growth factor in thyroid cell growth and function. J Endocrinol. 1998; 157(1): 5-12, indexed in Pubmed: 9614352.

17. Nickavar B, Mojab F, Javidnia K, et al. Chemical composition of the fixed and volatile oils of Nigella sativa L. from Iran. Z Naturforsch C. 2003; 58(9-10): 629-631, indexed in Pubmed: 14577620.

18. Ali BH, Blunden G. Pharmacological and toxicological properties of Nigella sativa. Phytother Res. 2003; 17(4): 299-305, doi: 10.1002/ptr.1309, indexed in Pubmed: 12722128.

19. Harzallah HJ, Grayaa R, Kharoubi W, et al. Thymoquinone, the Nigella sativa bioactive compound, prevents circulatory oxidative stress caused by 1,2-dimethylhydrazine in erythrocyte during colon postinitiation carcinogenesis. Oxid Med Cell Longev. 2012; 2012: 854065, doi: 10.1155/2012/854065, indexed in Pubmed: 22570743.

20. Dollah MA, Parhizkar S, Izwan M. Effect of Nigella sativa on the kidney function in rats. Avicenna J Phytomed. 2013; 3(2): 152-158, indexed in Pubmed: 25050269.

21. Monsour PA, Kruger BJ, Barnes A. Calcitonin cell population and distribution in the thyroid gland of the rat. J Morphol. 1985; 186(3): 271-278, doi: 10.1002/jmor.1051860304, indexed in Pubmed: 3910845.

22. Hsu SM, Raine L, Fanger H. Use of avidin-biotin-peroxidase complex $(\mathrm{ABC})$ in immunoperoxidase techniques: a com- 
parison between $\mathrm{ABC}$ and unlabeled antibody (PAP) procedures. J Histochem Cytochem. 1981; 29(4): 577-580, doi: 10.1177/29.4.6166661, indexed in Pubmed: 6166661.

23. Schwartz JE, Durham BC. Evaluation of three methods of protein analysis for serum and heart homogenates. Ann Clin Lab Sci. 1979; 9(2): 139-143, indexed in Pubmed: 453787.

24. Tipple T, Rogers L. Methods for the Determination of Plasma or Tissue Glutathione Levels. Developmental Toxicology. 2012: 315-324, doi: 10.1007/978-1-61779-867-2_20.

25. Weydert CJ, Cullen JJ. Measurement of superoxide dismutase, catalase and glutathione peroxidase in cultured cells and tissue. Nat Protoc. 2010; 5(1): 51-66, doi: 10.1038/ /nprot.2009.197, indexed in Pubmed: 20057381.

26. de Almeida AJ, Ribeiro TP, de Medeiros IA. Aging: Molecular Pathways and Implications on the Cardiovascular System. Oxid Med Cell Longev. 2017; 2017: 7941563, doi: 10.1155/2017/7941563, indexed in Pubmed: 28874954.

27. Torres SMF, Feeney DA, Lekcharoensuk C, et al. Comparison of colloid, thyroid follicular epithelium, and thyroid hormone concentrations in healthy and severely sick dogs. J Am Vet Med Assoc. 2003; 222(8): 1079-1085, indexed in Pubmed: 12710770.

28. Moskalenko R, Romanyuk A, Logvin A. Intrafollicular pressure of colloid thyroid gland determinate the type of folliculogenesis. Georgian Med News. 2012(205): 67-73, indexed in Pubmed: 22665734.

29. Bocian-Sobkowska J, Woźniak W, Malendowicz LK. Morphometric studies on the development of the human thyroid gland. II. The late fetal life. Histol Histopathol. 1997; 12(1): 79-84, indexed in Pubmed: 9046046.

30. Lee J, Yi S, Kang YE, et al. Morphological and Functional Changes in the Thyroid Follicles of the Aged Murine and Humans. J Pathol Transl Med. 2016; 50(6): 426-435, doi: 10.4132/ /jptm.2016.07.19, indexed in Pubmed: 27737529.

31. Griffin JE. Hypothyroidism in the elderly. Am J Med Sci. 1990; 299(5): 334-345, indexed in Pubmed: 2186631.

32. Cui H, Kong Y, Zhang H. Oxidative stress, mitochondrial dysfunction, and aging. J Signal Transduct. 2012; 2012: 646354, doi: 10.1155/2012/646354, indexed in Pubmed: 21977319.
33. Birben E, Sahiner UM, Sackesen C, et al. Oxidative stress and antioxidant defense. World Allergy Organ J. 2012; 5(1): 9-19, doi: 10.1097/WOX.0b013e3182439613, indexed in Pubmed: 23268465.

34. Baydas G, Reiter RJ, Nedzvetskii VS, et al. Altered glial fibrillary acidic protein content and its degradation in the hippocampus, cortex and cerebellum of rats exposed to constant light: reversal by melatonin. J Pineal Res. 2002; 33(3): 134-139, indexed in Pubmed: 12220326.

35. Viglietto G, Maglione D, Rambaldi M, et al. Upregulation of vascular endothelial growth factor (VEGF) and downregulation of placenta growth factor (PlGF) associated with malignancy in human thyroid tumors and cell lines. Oncogene. 1995; 11(8): 1569-1579, indexed in Pubmed: 7478581.

36. Klein M, Brunaud L, Muresan M, et al. Recombinant human thyrotropin stimulates thyroid angiogenesis in vivo. Thyroid. 2006; 16(6): 531-536, doi: 10.1089/thy.2006.16.531, indexed in Pubmed: 16839254.

37. Rohr-Udilova N, Klinglmüller F, Seif M, et al. Oxidative stress mediates an increased formation of vascular endothelial growth factor in human hepatocarcinoma cells exposed to erlotinib. Oncotarget. 2017; 8(34): 57109-57120, doi: 10.18632/ /oncotarget.19055, indexed in Pubmed: 28915658.

38. Taridi NM, Yahaya MF, Teoh SL, et al. Tocotrienol rich fraction (TRF) supplementation protects against oxidative DNA damage and improves cognitive functions in Wistar rats. Clin Ter. 2011; 162(2): 93-98, indexed in Pubmed: 21533313.

39. Badary OA, Gamal El-Din AM. Inhibitory effects of thymoquinone against 20-methylcholanthrene-induced fibrosarcoma tumorigenesis. Cancer Detect Prev. 2001; 25(4): 362-368, indexed in Pubmed: 11531013.

40. Ahlatci A, Kuzhan A, Taysi S, et al. Radiation-modifying abilities of Nigella sativa and thymoquinone on radiation-induced nitrosative stress in the brain tissue. Phytomedicine. 2014; 21(5): 740-744, doi: 10.1016/j.phymed.2013.10.023, indexed in Pubmed: 24268807.

41. Banerjee S, Padhye S, Azmi A, et al. Review on molecular and therapeutic potential of thymoquinone in cancer. Nutr Cancer. 2010; 62(7): 938-946, doi: 10.1080/01635581.2010.509832, indexed in Pubmed: 20924969.

Submitted: 18 December, 2017

Accepted after reviews: 9 July, 2018 Available as AoP: 24 June, 2018 